\title{
BMJ Open Organ manifestations and long-term outcome of Fabry disease in patients with the GLA haplotype D313Y
}

\author{
Daniel Oder, ${ }^{1,2}$ Nurcan Üçeyler, ${ }^{2,3}$ Dan Liu, ${ }^{1}$ Kai Hu, ${ }^{1}$ Bernhard Petritsch, ${ }^{4}$ \\ Claudia Sommer, ${ }^{2,3}$ Georg Ertl, ${ }^{1}$ Christoph Wanner, ${ }^{1,2}$ Peter Nordbeck ${ }^{1,2}$
}

To cite: Oder D, Üçeyler N, Liu D, et al. Organ manifestations and long-term outcome of Fabry disease in patients with the GLA haplotype D313Y. BMJ Open 2016;6: 010422. doi:10.1136/bmjopen-2015010422

- Prepublication history for this paper is available online. To view these files please visit the journal online (http://dx.doi.org/10.1136/ bmjopen-2015-010422).

Received 2 November 2015 Revised 2 March 2016 Accepted 3 March 2016

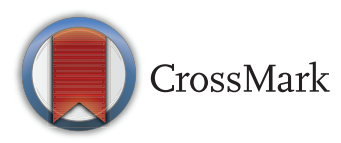

\footnotetext{
${ }^{1}$ Department of Internal Medicine I and Comprehensive Heart Failure Center (CHFC), University Hospital Würzburg, Würzburg, Germany ${ }^{2}$ Fabry Center for Interdisciplinary Therapy (FAZIT), University Hospital Würzburg, Würzburg,

Germany

${ }^{3}$ Department of Neurology, University Hospital Würzburg, Würzburg, Germany

${ }^{4}$ Department of Diagnostic and Interventional Radiology, University Hospital Würzburg, Würzburg, Germany
}

Correspondence to Dr Peter Nordbeck; nordbeck_p@ukw.de

\section{ABSTRACT}

Objectives: The severity of Fabry disease is dependent on the type of mutation in the $\alpha$ galactosidase $A(A g a l A)$ encoding gene (GLA). This study focused on the impact of the GLA haplotype D313Y on long-term organ involvement and function.

Setting and participants: In this monocentric study, all participants presenting with the D313Y haplotype between 2001 and 2015 were comprehensively clinically investigated at baseline and during a 4-year follow-up if available. Five females and one male were included.

Primary and secondary outcome measures: Cardiac, nephrological, neurological, laboratory and quality of life data.

Results: AgalA enzyme activity in leucocytes (0.3 $\pm 0.9 \mathrm{nmol} / \mathrm{min} / \mathrm{mg}$ protein $($ mean $\pm S D)$ ) and serum lyso-Gb3 $(0.6 \pm 0.3 \mathrm{ng} / \mathrm{mL}$ at baseline) were in normal range in all patients. Cardiac morphology and function were normal (left-ventricular (LV) ejection fraction 66 $\pm 8 \%$; interventricular septum $7.7 \pm 1.4 \mathrm{~mm}$; LV posterior wall $7.5 \pm 1.4 \mathrm{~mm}$; normalised LV mass in MRI $52 \pm 9 \mathrm{~g} /$ $\mathrm{m}^{2}$; LV global longitudinal strain $-21.6 \pm 1.9 \%$ ) and there were no signs of myocardial fibrosis in cardiac MRI. Cardiospecific biomarkers were also in normal range. Renal function was not impaired (estimated glomerular filtration rate MDRD $103 \pm 15 \mathrm{~mL} / \mathrm{min}$; serum-creatinine $0.75 \pm 0.07 \mathrm{mg} / \mathrm{dL}$; cystatin-c 0.71 $\pm 0.12 \mathrm{mg} / \mathrm{L}$ ). One female patient (also carrying a Factor $\mathrm{V}$ Leiden mutation) had a transitory ischaemic attack. One patient showed white matter lesions in brain MRI, but none had Fabry-associated pain attacks, pain crises, evoked pain or permanent pain. Health-related quality of life analysis revealed a reduction in individual well-being. At long-term follow-up after 4 years, no significant change was seen in any parameter.

Conclusions: The results of the current study suggest that the D313Y genotype does not lead to severe organ manifestations as seen in genotypes known to be causal for classical FD.

\section{INTRODUCTION}

Anderson-Fabry disease (FD) is an inherited $\mathrm{X}$ linked lysosomal storage disorder, caused by enzyme deficiency of $\alpha$-galactosidase A (AgalA), which leads to potentially

\section{Strengths and limitations of this study}

- This is the first non-case report study investigating the clinical impact of the GLA genotype D313Y in a group of respective participants.

- On the basis of the results, this mutation should be considered a non-pathological haplotype, which has important implications for therapy planning and prognosis in affected individuals.

- The main limitation is the small number of individuals investigated during follow-up and the lack of clinical data in participants exceeding the seventh decade in life, even though in affected patients Fabry disease usually manifests much earlier. Furthermore, only one male participant is included.

life-threatening accumulation of globotriaosylceramides (Gb3) in lysosome-carrying tissues. $^{1-5}$ In addition to gender, clinical manifestations and disease severity are largely dependent on the underlying GLA mutation. ${ }^{3} 467$ Initially described as a multisystemic disorder mainly involving the three organ systems of the heart, kidneys and nervous system, newer studies suggest that besides these 'classical' FD mutations involving a combination of pain, ${ }^{8} 9$ cryptogenic stroke at young age, ${ }^{9} 10$ myocardial fibrosis ${ }^{11} 12$ and pathological renal function, ${ }^{13}$ there might additionally exist mild, so-called 'late onset' and/or mono-phenotypical GLA mutation variants, which are in need of further clinical characterisation. $^{3-5}$ Among the currently known over 600 pathogenic GLA mutations, $^{15} 16$ the D313Y (Exon 6, c.937G.T) mutational variant has been reported to cause only mild clinical symptoms in observational case reports, suggesting a good prognosis and no need of specific therapy. ${ }^{17-20}$ However, owing to the currently only anecdotal data available, the long-term impact of the D313Y mutation on organ function still remains poorly understood, which hinders concluding therapeutic recommendations. 
The aim of this study was to improve the pathophysiological understanding of the D313Y genotype by observing the long-term changes in organ function in mutation carriers. Clinical, biomarker, health-related quality of life (HRQoL) and imaging data were analysed at baseline (BL) and during long-term follow-up (FUP) in all respective patients who were examined at the Fabry Center for Interdisciplinary Therapy (FAZIT) of the University Hospital Würzburg, Germany.

\section{METHODS}

Study population

The investigations were approved by the local ethics committee of the University and University Hospital Würzburg, Bavaria, Germany, and all patients gave written informed consent in accordance with the Declaration of Helsinki. Patients were identified during their stay at FAZIT for clinical evaluation and treatment. Genetic testing revealed the GLA mutation D313Y (Exon 6 , c.937G.T) in six patients from five different families (5 female; age $33 \pm 15$ years, range $18-51$ years at $\mathrm{BL}$ ). No additional GLA mutations or genetic polymorphisms were found in these individuals. Comprehensive clinical data and blood parameters were acquired at BL and during FUP after 4 years if available as described below.

\section{Family analysis}

Detailed family pedigrees were compiled in each patient. Family history was recorded including potential FD-related signs and symptoms, history of heart or kidney disease, cerebrovascular events, death at young age and respective causes of death.

\section{Clinical assessment}

All study participants underwent physical examination with particular focus on cardiac, renal and neurological signs and symptoms. Blood pressure, heart rate and the body mass index were determined.

\section{Electrocardiogram}

Standardised 12-channel ECGs were performed in all patients at rest and during cardiac stress test. Additionally, all patients received a $24 \mathrm{~h}$ Holter ECG at their first day of the visit.

\section{Echocardiography}

Standard two-dimensional (2D) echocardiography was performed in accordance with the current recommendations for cardiac chamber quantification by echocardiography in adults of the American Society of Echocardiography and the European Association of Cardiovascular Imaging. ${ }^{21}{ }^{22}$ The left ventricular (LV) parasternal long-axis images obtained by M-mode echocardiography (Vivid $7 \quad(3.5 \mathrm{MHz}), \quad$ GE Vingmed Ultrasound AS, Horten, Norway), were used in the determination of end-diastolic and end-systolic dimensions as well as for septal (IVSed) and LV posterior wall
(LVPWed) thicknesses. The LV ejection fraction (LVEF) was calculated based on the 2-chamber and 4-chamber views by using the Simpson's formula. The transmitral flow was determined by placing the Doppler window between the tips of the mitral valve leaflets, consecutively measuring the peak flow velocities in early ( $\mathrm{E}$ wave) and late (A wave) systole. Blood-pooled pulsed Doppler imaging of the mitral valve inflow was used to quantify the ratio of early-to-late (E/A) diastolic flow velocity and to gain the deceleration time. The standard apical views of the LV were acquired for offline quantification of myocardial deformation values by 2D speckle tracking using ECHO-Pac Software (GE Vingmed Ultrasound AS) as described before. ${ }^{23}{ }^{24}$ After manual selection of the region of interest (ROI) was sufficiently performed, the speckles were at first automatically assumed and then modified and confirmed by the user. 2D grey scale images were recorded with a frame rate of 60-80 frames per second and particular care was taken in ensuring that the entire ventricular wall was clearly visible in all frames. The system automatically tracked the tissue within the region and divided the myocardium into standard segments. The tracking was visually checked and, if necessary, adjusted. The trace analysis was automatically displayed after validating the tracking. LV global and segmental longitudinal peak systolic strain rate and strain values were extracted from basal, mid and apical segments of the septal and lateral walls.

\section{Cardiac MRI}

Cardiac MRI (cMRI) was performed on a $1.5 \mathrm{~T}$ full-body MRI scanner (Magnetom Symphony Quantum/Avanto, Siemens Medical Systems, Erlangen, Germany) in breathhold technique with ECG triggering. After morphological cine imaging using steady state free precession techniques, patients received gadopentetate dimeglumine (Bayer Health Care, Leverkusen, Germany) in the standard dose of $0.2 \mathrm{mmol} / \mathrm{kg}$ body weight per intravenous injection. Late contrast agent enhanced images were acquired using T1-weighted inversion recovery imaging sequences (field of view $240 \times 320 \mathrm{~mm}^{2}$, matrix size $165 \times 256$, slice thickness $8 \mathrm{~mm}$, echo time $3.4 \mathrm{~ms}$, repetition time $7.5 \mathrm{~ms}$ ). Consecutive short-axis slices covering the entire left ventricle were acquired and then used for manually measuring the myocardial volumes and areas with mid or transmyocardial late gadolinium enhancement (LGE).

\section{Neurological assessment}

All patients were examined neurologically and underwent standard electroneurography of the right sural nerve to exclude large fibre neuropathy following standard procedures. ${ }^{25}$ Quantitative sensory testing (QST) was performed following the protocol of the German Research Network for the Study of Neuropathic Pain (Deutscher Forschungsverbund Neuropathischer Schmerz) ${ }^{25}$ Using a calibrated device (Somedic, Hörby, Sweden), thermal and mechanical perception and pain 
thresholds were assessed. To determine intraepidermal nerve fibre density (IENFD), two $5 \mathrm{~mm}$ skin punch biopsies (Stiefel GmbH, Offenbach, Germany) were obtained in local anaesthesia from the lateral lower leg and the back at thoracic vertebrae 10 level and processed as described earlier. ${ }^{26}$ IENFD was determined according to published rules. ${ }^{27}$ For the assessment of potential brain involvement, patients underwent brain MRI (bMRI) on a $3 \mathrm{~T}$ full-body MRI scanner. Contiguous slices in axial and coronary orientation were acquired to cover the whole brain, including T1-weighted, T2-weighted, proton density-weighted, and diffusion-weighted, as well as 2D/3D time-of-flight/fluid-attenuated inversion recovery MR-angiography pulse sequences. To semiquantitatively assess cerebral white matter lesion load, we applied the Fazekas score for each participant on the FLAIR sequences. The Fazekas score ranges from 0 to 3 with zero $=$ no or a single punctuate white matter lesion, $1=$ multiple punctuate lesions, $2=$ beginning confluence of lesions, $3=$ large confluent lesions. ${ }^{28}$

\section{Laboratory tests and biomarkers}

Patients' renal function was determined by measuring (99-Technetium diethylenetriamine penta-acetic acid (DTPA)-clearance) and/or estimating glomerular filtration rates (MDRD formula), serum-creatinine (reference: $0-0.95 \mathrm{mg} / \mathrm{dL}$ ) and cystatin c (reference: 0.61$0.95 \mathrm{mg} / \mathrm{dL}$ ). Albuminuria and proteinuria were determined by urinary albumin-to-creatinine ratio (reference: $<30 \mathrm{mg} / \mathrm{g}$ creatinine) and urinary protein-to-creatinine ratio (reference: $<70 \mathrm{mg} / \mathrm{g}$ creatinine). For detection of myocardial involvement, the N-terminal pro-brain natriuretic peptide (NT-proBNP, reference: $<125 \mathrm{pg} / \mathrm{mL}$ ) and cardiac high-sensitive troponin $\mathrm{T}$ (hs-TnT, reference: $<14 \mathrm{pg} / \mathrm{mL}$ ) were determined. Serum lyso-Gb3 (reference: $<0.9 \mathrm{ng} / \mathrm{mL}$ ) and agalA enzyme activity in leucocytes (reference: $0.4-1.0 \mathrm{nmol} / \mathrm{min} / \mathrm{mg}$ protein) were measured by Centogene (Rostock, Germany) as potential indicators for disease severity. ${ }^{29-31}$

\section{Assessment of health-related quality of life}

HRQoL was assessed using data of the Medical Outcomes Study SF-36 questionnaire at two visits, BL and the latest available FUP. ${ }^{32}$ The SF-36 is a wellestablished and transferable instrument to investigate the HRQoL in different diseases. ${ }^{32-34}$ The questions cover areas like daily life activities, physical functioning and social well-being. Two summary scales, the physical component summary score (PCSS) and the mental component summary score (MCSS), as well as eight further scales do describe various physical and mental grades of HRQoL that are determined; the sum scores range from 0 (completely impaired) to a maximum of 100 (completely improved). ${ }^{.5}$

\section{Statistical analysis}

All continuous data are presented either as an absolute number, as mean value \pm the $\mathrm{SD}(\operatorname{mean} \pm \mathrm{SD})$, or as a median value with IQRs (MW $\pm \mathrm{IQR})$. The categorical variables are presented as percentages $(\%)$. The differences on the strain rate and strain values among the basal, mid and apical levels were compared by using one-way analyses of variance followed by Tukey's multiple comparison post hoc tests when appropriate. Statistical significance was assumed at a $\mathrm{p}$ value $<0.05$. The statistical analysis was performed using IBM SPSS Statistics, V.23.0 (SPSS Inc., Chicago, Illinois, USA).

\section{RESULTS}

\section{Symptoms leading to FD screening}

Two of the six participants (\#2 and \#5) were identified due to dermal manifestations of unclear origin (later diagnosed as rubeosis faciei and atopic dermatitis) followed by skin biopsy. Typical macroscopic angiokeratoma, which are often seen in classic FD, were not found. Both of these patients reported no further symptoms. Patient \#1 was detected by family screening, after his daughter (patient \#2) had been diagnosed by skin biopsy. Patient \#6 was identified due to alterations in bMRI scans that were performed because of persistent vertigo, raising a suspicion of multiple sclerosis, which was, however, not confirmed. The remaining two patients were introduced to our centre due to a recent history of a suspected cryptogenic neurological event: patient \#3 reported episodic weakness of the right side lasting for approximately $30 \mathrm{~min}$ at the age of 14 without any morphological evidence of stroke in bMRI. In this patient, enzyme replacement therapy (ERT) was started after the diagnosis of FD. Later, the D313Y mutation was confirmed and ERT was stopped. Increasing sensory symptoms including pathological heat sensation and worsening of heat intolerance within 1 year after ERT cessation were successfully treated with analgesic drugs. The second patient (\#4) suffered from a single transient episode of aphasia at the age of 44 , which was accompanied by transient paresis of her left arm.

\section{Clinical and FD-related laboratory data}

Five out of the six patients were female, all young to middle-aged (33 \pm 15 , range $18-51$ years), and regularly attended FAZIT for evaluation of their clinical status and therapy planning. The mean body mass index was 26.7 $\pm 9 \mathrm{~kg} / \mathrm{m}^{2}$. Resting blood pressure and heart rate were all in physiological ranges $(118 \pm 9 / 80 \pm 10 \mathrm{~mm} \mathrm{Hg}, 84 \pm 17$ / $\mathrm{min})$. AgalA activity $(0.33 \pm 0.09 \mathrm{nmol} / \mathrm{min} / \mathrm{mg}$ protein, reference: $0.4-1.0 \mathrm{nmol} / \mathrm{min} / \mathrm{mg}$ protein or $*$ reference: $0.36-0.84 \mathrm{MU} / \mathrm{mg}$; see table 1$)$ and lyso-Gb3 (0.6 $\pm 0.3 \mathrm{ng} / \mathrm{mL}$, reference: $\leq 0.9 \mathrm{ng} / \mathrm{mL}$ ) were also normal (table 1).

\section{Cardiac assessment \\ ECG}

All patients were in sinus rhythm and resting ECG was overall non-pathological in all patients. 
Table 1 Baseline characteristics in patients with FD with the D313Y GLA genotype

\begin{tabular}{|c|c|c|c|c|c|c|c|}
\hline Variable/participant (\#) & 1 & 2 & 3 & 4 & 5 & 6 & Mean \pm SD $/ \%$ \\
\hline \multicolumn{8}{|l|}{ Demographics } \\
\hline Age (years) & 51 & 21 & 19 & 44 & 18 & 43 & $33 \pm 15$ \\
\hline Gender (male/female) & Male & Female & Female & Female & Female & Female & 1/6 (17/83\%) \\
\hline $\mathrm{BMI}\left(\mathrm{kg} / \mathrm{m}^{2}\right)$ & 22.1 & 24.8 & 21.8 & 29.8 & 43.5 & 18.1 & $26.7 \pm 9$ \\
\hline Age at diagnosis (years) & 51 & 21 & 14 & 44 & 18 & 43 & $32 \pm 16$ \\
\hline \multicolumn{8}{|l|}{ Biomarkers } \\
\hline Serum lyso-Gb3 (ng/mL) & LLOQ & 0.23 & 0.9 & 0.7 & 0.5 & 0.7 & $0.6 \pm 0.3$ \\
\hline AgalA (nmol/min/mg prot.) & 0.32 & 0.32 & $0.81^{*}$ & 0.45 & NA & 0.23 & $0.33 \pm 0.9$ \\
\hline NT-proBNP $(p g / m L)$ & 49 & 30 & 229 & 56 & 77 & 38 & $80 \pm 75$ \\
\hline hs-TnT (pg/mL) & NA & $<5$ & NA & $<5$ & $<5$ & $<5$ & $<5$ \\
\hline \multicolumn{8}{|l|}{ Cardiovascular } \\
\hline $\mathrm{SBP}(\mathrm{mm} \mathrm{Hg})$ & 115 & 125 & 120 & 132 & 107 & 110 & $118 \pm 9$ \\
\hline $\mathrm{DBP}(\mathrm{mm} \mathrm{Hg})$ & 80 & 87 & 75 & 97 & 68 & 74 & $80 \pm 10$ \\
\hline $\mathrm{HR}(\mathrm{bpm})$ & 63 & 89 & 72 & 101 & 73 & 104 & $84 \pm 17$ \\
\hline \multicolumn{8}{|l|}{ Echocardiography } \\
\hline LVEF (\%) & 69 & 69 & 60 & 60 & 61 & 79 & $66 \pm 8$ \\
\hline LVDED (mm) & 49 & 42 & 45 & 47 & 47 & 34 & $44 \pm 5$ \\
\hline LVDES (mm) & 33 & 27 & 32 & 24 & 27 & 23 & $28 \pm 4$ \\
\hline IVSed (mm) & 7 & 8 & 6 & 9 & 8 & 6 & $8 \pm 1$ \\
\hline LVPWed (mm) & 7 & 7 & 6 & 9 & 8 & 6 & $8 \pm 1$ \\
\hline $\mathrm{E} / \mathrm{A}$ & 1.6 & 1.2 & 1.8 & 1.0 & 1.5 & 1.2 & $1.4 \pm 0.3$ \\
\hline DT (ms) & 152 & 241 & 161 & 163 & 101 & 178 & $166 \pm 45$ \\
\hline \multicolumn{8}{|l|}{ Speckle tracking strain (\%) } \\
\hline Global strain & -20.75 & -18.13 & -23.06 & -21.75 & -23.06 & -22.81 & $-21.6 \pm 1.9$ \\
\hline Basal strain & -17.25 & -14.19 & -17.90 & -17.34 & -20.27 & -17.86 & $-17.47 \pm 2$ \\
\hline Mid-strain & -19.84 & -18.11 & -19.12 & -19.59 & -22.40 & -19.88 & $-19.8 \pm 1.4$ \\
\hline Apical strain & -26.25 & -22.71 & -30.76 & -27.62 & -26.70 & -30.57 & $-27.4 \pm 3$ \\
\hline Septal strain & -21.48 & -19.47 & -22.19 & -20.54 & -22.24 & -24.61 & $-21.8 \pm 1.8$ \\
\hline Lateral strain & -20.74 & -17.20 & -22.99 & -22.49 & -24.01 & -20.92 & $-23.25 \pm 1.1$ \\
\hline \multicolumn{8}{|c|}{ Speckle tracking strain rate $\left(S-{ }^{1}\right)$} \\
\hline Global strain rate & -1.11 & -0.98 & -1.18 & -1.38 & -1.08 & -1.77 & $-1.25 \pm 0.3$ \\
\hline Basal strain rate & -1.08 & -0.98 & -1.18 & -1.18 & -1.04 & --1.48 & $-1.15 \pm 0.2$ \\
\hline Mid-strain rate & -1.06 & -1.05 & -0.99 & -1.18 & -1.10 & -1.66 & $-1.17 \pm 0.3$ \\
\hline Apical strain rate & -1.54 & -1.42 & -1.31 & -1.77 & -1.43 & -2.65 & $-1.69 \pm 0.5$ \\
\hline Septal strain rate & -1.23 & -1.10 & -1.14 & -1.21 & -1.16 & -1.86 & $-1.28 \pm 0.3$ \\
\hline Lateral strain rate & -1.22 & -1.20 & -1.18 & -1.54 & -1.22 & -2.00 & $-1.39 \pm 0.3$ \\
\hline \multicolumn{8}{|l|}{ Cardiac MRI } \\
\hline LGE (yes/no) & NA & no & no & no & no & no & $0 \%$ \\
\hline$n \operatorname{LVM}\left(\mathrm{g} / \mathrm{m}^{2}\right)$ & NA & 52 & 44 & 64 & 57 & 43 & $52 \pm 9$ \\
\hline $\mathrm{n} \operatorname{ESV}\left(\mathrm{mL} / \mathrm{m}^{2}\right)$ & NA & 21 & 25 & 34 & 22 & 28 & $26 \pm 5$ \\
\hline $\mathrm{n} \operatorname{EDV}\left(\mathrm{mL} / \mathrm{m}^{2}\right)$ & NA & 67 & 66 & 71 & 73 & 56 & $67 \pm 7$ \\
\hline $\mathrm{n} S V\left(\mathrm{~mL} / \mathrm{m}^{2}\right)$ & NA & 46 & 41 & 37 & 52 & 39 & $43 \pm 6$ \\
\hline $\mathrm{Cl}\left(\mathrm{l} / \mathrm{min} / \mathrm{m}^{2}\right)$ & NA & 4.0 & 3.1 & 3.2 & 3.7 & 4.2 & $3.6 \pm 0.5$ \\
\hline LVEF (\%) & NA & 68 & 62 & 52 & 70 & 69 & $64 \pm 7.5$ \\
\hline
\end{tabular}

AgalA, enzyme activity in leucocytes, reference: $0.4-1.0 \mathrm{nmol} / \mathrm{min} / \mathrm{mg}$ protein or *reference: $0.36-0.84 \mathrm{MU} / \mathrm{mg}$.

$\mathrm{BMI}$, body-mass-index in $\mathrm{kg} / \mathrm{m}^{2} ; \mathrm{Cl}$, cardiac index in cardiac; DT, deceleration time; HR, heart rate in bpm; hs-TnT, high-sensitive Troponin T, reference: $<14 \mathrm{pg} / \mathrm{mL}$; IVSed, interventricular septum thickness in end-diastole; LGE, late gadolinium enhancement; LLOQ, lower limit of quantification; LVDED, left ventricular diameter in end-diastole; LVDES, left ventricular diameter in end-systole; LVEF, left ventricular ejection fraction; LVPWed, left ventricular posterior wall thickness in end-diastole; Lyso-Gb3 reference: $<0.9 \mathrm{ng} / \mathrm{mL}$; MRI; DBP, diastolic blood pressure; $n$ EDV, normalised end-diastolic volume in cardiac MRI; $n$ ESV, normalised end-systolic volume in cardiac MRI; $n$ LVM, normalised left ventricular mass in cardiac MRI; $n$ SV, normalised stroke volume in cardiac MRI; NA, not available; NT-proBNP, N-terminal pro-brain natriuretic peptide, reference: age-dependent, $<125 \mathrm{pg} / \mathrm{mL}$; SBP, systolic blood pressure; SR=sinus rhythm.

\section{Exercise stress test}

Exercise stress testing showed physiological to only mildly reduced exercise capacities in all patients. Maximal watts were $131 \pm 32$, the maximal HR $164 \pm 6$, being $89 \pm 9 \%$ of the age-predicted HR, respectively. Two patients (\#4 and \#6) reached the age-predicted HR, while the others discontinued stress test due to fatigue or peripheral pain. No patient suffered from angina pectoris and there were no ECG abnormalities during or after exercise stress test.

Holter monitoring

Twenty four hour Holter monitoring did not reveal any significant or malignant arrhythmia; only patients \#4 
and \#6 suffered from mild sinus tachycardia with a mean heart rate of 108/min (minimum 99/min and maximum $116 / \mathrm{min}$ ) in patient $\# 4$ and $97 / \mathrm{min}$ (minimal heart rate $60 / \mathrm{min}$ at $1: 30$ and maximal heart rate of 142/min at 18:00) in patient \#6.

\section{Cardiac biomarkers}

The cardio-specific biomarkers hs-TnT (all $<5 \mathrm{pg} / \mathrm{mL}$, reference: $<14 \mathrm{pg} / \mathrm{mL})$ and NT-proBNP $(80 \pm 75 \mathrm{pg} / \mathrm{mL}$, reference: age-dependent, $<125 \mathrm{pg} / \mathrm{mL}$ ) were in normal ranges, indicating no cardiac involvement (table 1).

\section{Cardiac imaging}

Standard 2D-echocardiography (LV septum thickness $7.7 \pm 1.4 \mathrm{~mm}$ and posterior-wall thickness $7.5 \pm 1.4 \mathrm{~mm}$; figure $1 \mathrm{~A}, \mathrm{~B})$ and speckle tracking analysis showed no cardiac hypertrophy or reduced strain rate values (LV global longitudinal strain $-21.6 \pm 1.9 \%$; figure $1 \mathrm{C}, \mathrm{D})$, but LVEF in normal ranges $(66 \pm 8 \%)$. Matching this, cMRI studies revealed no signs of cardiac hypertrophy (normalised left ventricular mass (LVM): $52 \pm 9 \mathrm{~g} / \mathrm{m}^{2}$; figure $1 \mathrm{E}, \mathrm{F}$ ) and no LGE (figure $1 \mathrm{G}, \mathrm{H}$, and table 1). For comparison, representative images of a patient with a classical Fabry cardiomyopathy are given in figure 1I-P.

\section{Renal assessment}

Renal function was normal with a measured glomerular filtration rate (GFR) (99-Technetium DTPA-clearance) of $124 \pm 6 \mathrm{~mL} / \mathrm{min}$, serum-creatinine of $0.75 \pm 0.07 \mathrm{mg} / \mathrm{dL}$ (reference: $0-0.95 \mathrm{mg} / \mathrm{dL}$ ) and cystatin-c of 0.71 $\pm 0.12 \mathrm{mg} / \mathrm{L} \quad(0.61-0.95 \mathrm{mg} / \mathrm{dL})$. Proteinuria was not detected in any urine sample (table 2 ).

\section{Neurological assessment}

Neurological examination was normal in all patients.
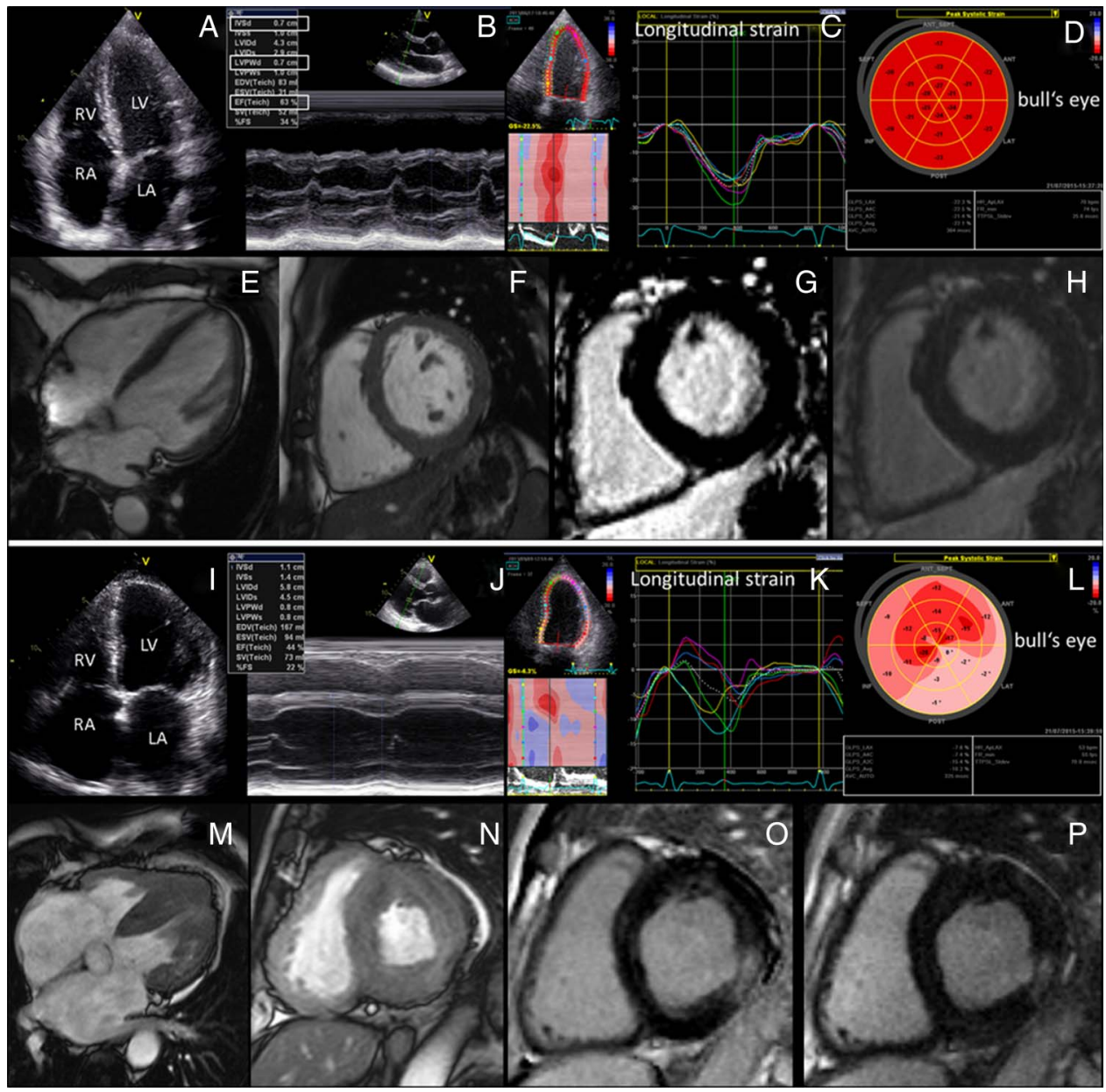

Figure 1 Cardiac morphology and function of a representative D313Y patient versus a patient with classical Fabry disease and advanced Fabry cardiomyopathy. (A-H) In D313Y patients (participant \#3), no signs of cardiac hypertrophy or diastolic dysfunction can be seen. (I-P) Fabry cardiomyopathy in respective genotypes is characterised by advanced hypertrophic thickening of the interventricular septum and the left ventricular posterior wall with left atrial dilation and reduced left ventricular ejection fraction in advanced stages. Moreover, 2D-speckle tracking reveals reduced longitudinal strain $(\mathrm{K})$ with extensive replacement fibrosis visualised by bull's eye in loco typico for Fabry cardiomyopathy (L). Morphologic and LGE cardiac MRI illustrate the difference in cardiac wall thickness between D313Y patients without cardiac involvement $(\mathrm{E}-\mathrm{H})$ compared to patients with advanced Fabry cardiomyopathy (M-P). 
Table 2 Baseline characteristics of Fabry-associated organ manifestations and symptoms in patients with the D313Y genotype

\begin{tabular}{|c|c|c|c|c|c|c|c|}
\hline $\begin{array}{l}\text { Variable/participant (\#) } \\
\text { Gender (male/female) }\end{array}$ & $\begin{array}{l}1 \\
\text { Male } \\
\end{array}$ & $\begin{array}{l}2 \\
\text { Female } \\
\end{array}$ & $\begin{array}{l}3 \\
\text { Female } \\
\end{array}$ & $\begin{array}{l}4 \\
\text { Female } \\
\end{array}$ & $\begin{array}{l}5 \\
\text { Female } \\
\end{array}$ & $\begin{array}{l}6 \\
\text { Female } \\
\end{array}$ & $\begin{array}{l}\text { Mean } \pm S D / \% \\
1 / 6(17 / 83 \%)\end{array}$ \\
\hline \multicolumn{8}{|l|}{ Renal } \\
\hline Serum-creatinine (mg/dL) & 0.8 & 0.7 & 0.8 & 0.7 & 0.67 & 0.85 & $0.8 \pm 0.1$ \\
\hline Cystatin C (mg/L) & 0.62 & 0.55 & 0.71 & 0.71 & 0.74 & 0.90 & $0.7 \pm 0.1$ \\
\hline GFR in 99Tc-DTPA Clearance (mL/min) & 124 & 123 & 130 & 125 & 129 & 113 & $124 \pm 6$ \\
\hline eGFR $(\mathrm{mL} / \mathrm{min} / 1.73 \mathrm{qm})$ & 108 & 112 & 98 & 97 & 122 & 78 & $103 \pm 15$ \\
\hline UACR (mg/gL) & LLOQ & LLOQ & LLOQ & 5.8 & LLOQ & LLOQ & LLOQ \\
\hline UPCR (mg/gL) & 79 & 72 & $<50$ & 56 & 52 & $<50$ & 60 \\
\hline \multicolumn{8}{|l|}{ Fabry-associated organ manifestations } \\
\hline Angiokeratoma & no & no & no & no & yes & no & 17 \\
\hline Cornea verticillata & no & no & no & no & no & no & 0 \\
\hline Frequent diarrhoea & yes & no & no & no & no & no & 17 \\
\hline Vertigo & no & no & yes & no & no & yes & 33 \\
\hline Tinnitus & no & no & yes & no & no & no & 17 \\
\hline \multicolumn{8}{|l|}{ Neurology } \\
\hline Hypohidrosis & no & no & yes & no & no & yes & 33 \\
\hline Heat intolerance & no & no & yes & yes & no & yes & 50 \\
\hline Cold intolerance & no & no & no & no & no & no & 0 \\
\hline History of TIA & no & no & (yes) & yes & no & no & 33 \\
\hline History of cerebrovascular insult & no & no & no & no & no & no & 0 \\
\hline White matter lesions & NA & no & no & no & no & yes & 20 \\
\hline Pain other than Fabry-associated & yes & no & yes & no & no & yes & 50 \\
\hline \multicolumn{8}{|l|}{ Fabry-associated pain* } \\
\hline Pain attacks $†$ & no & no & no & no & no & no & 0 \\
\hline Pain crises $¥$ & no & no & no & no & no & no & 0 \\
\hline Evoked pain§ & no & no & no & no & no & no & 0 \\
\hline Permanent pain & no & no & no & no & no & no & 0 \\
\hline \multicolumn{8}{|l|}{ Health related quality of life (SF-36) } \\
\hline Physical functioning & 80 & 100 & 80 & 90 & NA & 85 & $87 \pm 8$ \\
\hline Role physical & 25 & 100 & 50 & 100 & NA & 75 & $70 \pm 33$ \\
\hline Bodily pain & 31 & 41 & 41 & 100 & NA & 51 & $53 \pm 27$ \\
\hline General Health & 57 & 87 & 25 & 57 & NA & 57 & $57 \pm 22$ \\
\hline Vitality & 40 & 75 & 35 & 70 & NA & 80 & $60 \pm 21$ \\
\hline Social functioning & 87.5 & 100 & 62.5 & 100 & NA & 87.5 & $88 \pm 15$ \\
\hline Role emotional & 33.33 & 100 & 100 & 100 & NA & 100 & $87 \pm 30$ \\
\hline Mental health & 40 & 88 & 60 & 72 & NA & 76 & $67 \pm 18$ \\
\hline Physical component summary score & 42.2 & 49.44 & 35.87 & 53.72 & NA & 43.28 & $45 \pm 7$ \\
\hline Mental component summary score & 36.85 & 56.62 & 46.37 & 52.54 & NA & 56.68 & $50 \pm 9$ \\
\hline
\end{tabular}

Participants \#1-3 later also underwent clinical follow-up.

${ }^{*}$ Fabry-associated pain=characteristic pain phenotypes (pain attacks, pain crises, evoked pain, permanent pain) reported by patients with Fabry disease.

tpain attacks=mostly triggered episodic pain that starts suddenly, remains for a certain time period and then disappears.

fpain crisis=episodic pain of extreme severity; starts mostly at hands and feet and spreads over the entire body lasting for hours and/or days; mostly resistant to analgesic treatment.

§evoked pain=allodynia (pain on stimulation with a non-painful stimulus) and/or hyperalgesia (increased pain sensitivity on stimulation with a painful stimulus).

Ipermanent pain=pain that is present for $24 \mathrm{~h}$ or during most of the time of a day.

Cystatin c, reference: $0.61-0.95 \mathrm{mg} / \mathrm{dL}$.

GFR, glomerular filtration rate; serum-creatinine reference: $0-0.95 \mathrm{mg} / \mathrm{dL}$; eGFR, estimated GFR (MDRD formula); LLOQ, lower limit of quantification; NA, not available; TIA, transient ischaemic attack; UACR, urinary albumin-to-creatinine ratio, reference: $<30 \mathrm{mg} / \mathrm{g}$ creatinine; UPCR, urinary protein-to-creatinine ratio, reference: $<70 \mathrm{mg} / \mathrm{g}$ creatinine.

Pain

None of the six patients had Fabry-associated pain attacks, pain crises, evoked pain or permanent pain. ${ }^{8}$ One male patient (\#1) suffered from episodic neck and back pain due to disc herniation. One female patient reported episodic pain in the hands and knees at BL visit, while pain was denied at 2 years FUP and tension type headache and medication overuse headache was diagnosed (\#3). One female patient reported of episodic pain in the lateral hands and fingers (\# 6).

Nerve conduction studies

Nerve conduction studies of the right sural nerve were normal in all cases (median nerve conduction velocity 
$47 \mathrm{~m} / \mathrm{s}$, range $44-58 \mathrm{~m} / \mathrm{s}$; median sensory nerve action potential amplitude $28 \mu \mathrm{V}$, range $14-34 \mu \mathrm{V}$ ).

\section{Quantitative sensory testing}

Compared with the published normative values, ${ }^{36}$ thermal and mechanical perception and pain thresholds assessed at the dorsal foot were normal in all cases when assessed with QST.

\section{IENFD in skin biopsy}

IENFD obtained from skin punch biopsies from the lateral lower leg (median 8 fibres/mm, range 4-12 fibres $/ \mathrm{mm}$ ) and the back (median 32 fibres $/ \mathrm{mm}$, range 16-41 fibres $/ \mathrm{mm}$ ) was normal in all investigated patients, except for a slight reduction in distal IENFD to 4.3 fibres/mm (normal range $6-12$ fibres $/ \mathrm{mm}$ ) in one patient (\#1).

\section{Cerebrovascular events}

One female patient (\#4) had suffered a TIA in the median cerebral artery (MCA) territory with temporary speech problems and weakness in the left arm. However, a factor-V-Leiden thrombophilia mutation was also detected in this patient as a confounding risk factor for cerebrovascular events.

\section{Brain MRI}

In the bMRI scan of the patient with suspected TIA (patient \#4), a small gliotic area was found in the right occipital region, which is independent of the reported episodic aphasia and weakness in the left arm. In the bMRI of patient \#6, confluent periventricular white matter lesions were seen, initially raising a suspicion of multiple sclerosis (Fazekas score 3). In all other patients, normal bMRI scans with a Fazekas score of 0 were found.

\section{Hypohidrosis}

Hypohidrosis was reported by two patients at BL.

\section{Dermal assessment}

Two of six patients (\#2 and \#5) showed dermal abnormalities initiating additional diagnostics including skin biopsy. However, these dermal manifestations were later clinically categorised as atypical of FD. Electron microscopic examinations were not conducted.

\section{Gastrointestinal assessment}

Patient \#1 experienced chronic diarrhoea lasting for approximately 6 months. No gastrointestinal discomfort was reported by any of the other five patients.

\section{Family analysis}

Family analysis was inconspicuous for history of relevant heart disease with premature or sudden cardiac death, chronic kidney disease, dialysis and/or of cryptogenic stroke at young age in any patient's family. The majority of family members refused genetic analysis (figure 2), mainly due to missing or mild symptoms. Interestingly, patient \#6 reported symptoms of hand pain after exercise or during hot summer months in her 8-year-old son, who, however, was not yet genetically tested or examined.

\section{Health-related quality of life}

HRQoL was assessed with physical component summary scores (PCSS mean $=44.29$; range 35.87-53.72) and mental component summary scores (MCSS mean $=51.86$, range 46.37-56.68), both revealing a reduction of individual well-being as a reflection of the subjective disease burden (table 2).

\section{Four year follow-up}

Long-term FUP investigations were performed after 4.2 \pm 1.4 years in three patients who followed the FAZIT recommendations for re-evaluation due to unclear pathogenicity of the D313Y genotype. The three other participants were all newly diagnosed and clinically
Figure 2 Family pedigree of a representative female patient (participant \#4) with proven D313Y GLA genotype. The index patient was identified due to a history suggestive of a transient ischaemic attack with episodic aphasia and weakness of the left arm. She additionally carries a heterozygous Factor $\mathrm{V}$ Leiden thrombophilia mutation as a co-founding risk factor of ischaemic events. In contrast to the findings in patients with 'classical' Fabry disease, none of the index patient's family members were willing to investigate their genetic material for the presence of a Fabry disease causing mutation as none of them were reported to

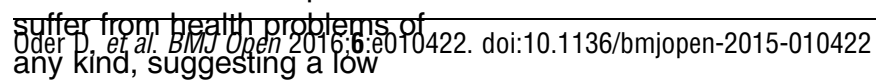
penetrance of pathology in D313Y compared to other GLA

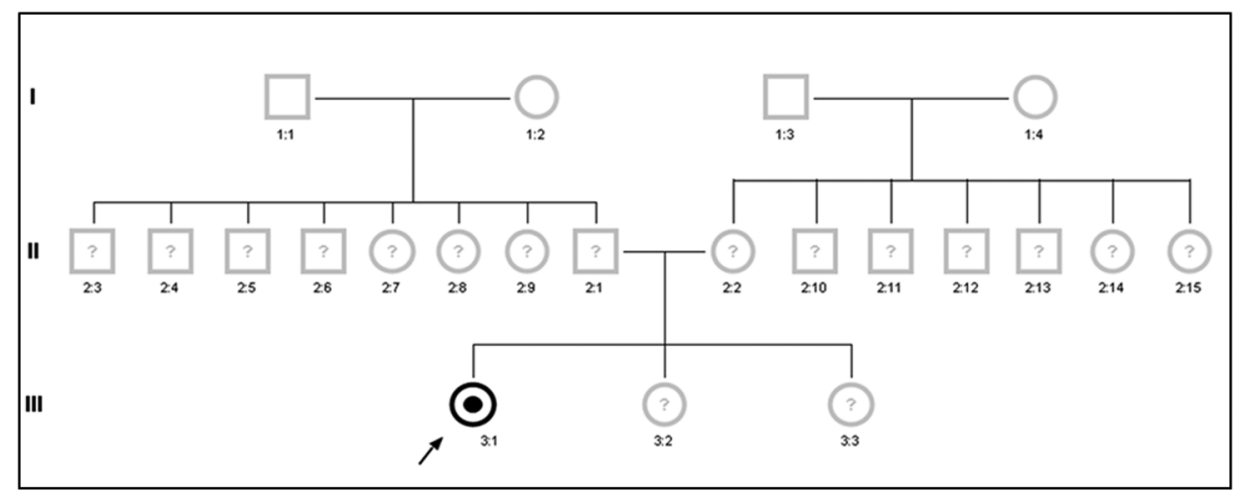


investigated first in 2015. Resting blood pressure $(121 \pm 16 / 78 \pm 6 \mathrm{~mm} \mathrm{Hg})$, heart rate $(69 \pm 6 / \mathrm{min})$ and BMI $\left(22 \pm 2 \mathrm{~kg} / \mathrm{m}^{2}\right)$ all remained in non-pathological ranges (table 3). All patients had sinus rhythm in resting ECG and no rhythm abnormality was revealed during Holter monitoring. In exercise stress testing, patients reached a maximum performance of $125 \pm 0$ watts and a maximal HR of $135 \pm 16(72 \pm 5 \%$ of the age-predicted HR). No patient suffered from angina pectoris or showed ECG abnormalities during or after exercise stress test, which was discontinued due to fatigue $(66 \%)$ or knee pain $(33 \%)$.

Lyso-Gb3 at FUP was stable at low levels $(0.5 \pm 0.4 \mathrm{ng} /$ $\mathrm{mL}$, reference: $\leq 0.9 \mathrm{ng} / \mathrm{mL}$ ). Hs-TnT remained $<5 \mathrm{pg} /$ $\mathrm{mL}$ (reference: $<14 \mathrm{pg} / \mathrm{mL}$ ) in all patients and NTproBNP was $42 \pm 11 \mathrm{pg} / \mathrm{mL}$ (reference: age-dependent, $<125 \mathrm{pg} / \mathrm{mL}$ ). LV septum was $7.3 \pm 0.6 \mathrm{~mm}$ and the posterior-wall $7.3 \pm 0.6 \mathrm{~mm}$ in 2D-echocardiography and normalised LVM in cMRI $50 \pm 2 \mathrm{~g} / \mathrm{m}^{2}$ indicating no progress in cardiac hypertrophy. Left ventricular ejection fraction was $61 \pm 5 \%$. cMRI and 2D-speckle tracking results were normal, showing no LGE or reduced strain rate values (LV global longitudinal strain $-18.5 \pm 2.3 \%$ ). The estimated GFR (MDRD formula) was $90 \pm 16 \mathrm{~mL}$ / min, serum-creatinine $0.88 \pm 0.18 \mathrm{mg} / \mathrm{dL}$ (reference: $0-0.95 \mathrm{mg} / \mathrm{dL}$ ) and cystatin-c $0.77 \pm 0.13 \mathrm{mg} / \mathrm{L}$ (reference: $0.61-0.95 \mathrm{mg} / \mathrm{dL}$ ). No proteinuria was detected in any investigated urine sample. Long-term evaluation of neurological involvement was normal in all patients with no Fabry-associated pain attacks, pain crises, evoked pain or permanent pain as already reported at BL. Nerve conduction studies of the right sural nerve and thermal and mechanical perception and pain thresholds assessed in the dorsal foot were in normal range. In patient \#1, IENFD was analysed again at 5-year FUP, revealing equal results in the lateral lower leg ( 4 fibres/mm at BL and FUP), and still normal IENFD in the back (26.5 fibres/ $\mathrm{mm}$ instead of 19.2 fibres $/ \mathrm{mm}$ at BL). Patient \#6 received five repetitive bMRI scans over 4 years, which were performed due to confluent periventricular white matter lesions (Fazekas Score 3), initially raising a suspicion of multiple sclerosis (figure 3A,B). From 2010 to 2015, there was no significant change in bMRI. In all other patients, normal bMRI scans with Fazekas scores of 0 were found. Only patient \#3 reported continued hypohidrosis similar as already reported at the BL visit. No potentially Fabry-associated gastrointestinal symptoms were reported at FUP except for patient \#1 with occasional non-specific diarrhoea.

\section{DISCUSSION}

Over the past years, increasing efforts have been made to reveal benign, atypical and/or organ-specific mutation variants of the GLA in patients with FD. To date, over 600 mutations potentially causing FD have been reported, ${ }^{15}{ }^{16}$ but the specific clinical impact of most mutations is not yet well explored. Identifying the clinical impact of individual mutations is therefore of great clinical importance, particularly in order to make therapeutic decisions. In the present long-term FUP study, we show that the D313Y mutation does not cause severe cardiac, kidney or neurological impairments as seen in mutation carriers of 'classical' forms of FD.

\section{State-of-the-art-what is yet known?}

Previous studies reported a high frequency of non-organ-destructive but still potentially pathogenic categorised GLA mutation variants in the general population. For the variant D313Y, a prevalence of $0.5 \%$ in the general population has been described. ${ }^{18} \quad 20$ Molecularly, the pathogenic correlate of the D313Y GLA mutation is a guanine-to-tyrosine conversion taking place in codon 313, leading to aspartic acid-to-tyrosine substitution. ${ }^{19}$ In contrast to the first description that considered D313Y to cause a classical pathogenic variant of $\mathrm{FD},{ }^{37}$ later case reports described only mild symptoms in patients with the D313Y genotype, therefore suggesting a pseudo-deficiency of AgalA. ${ }^{17} 1820$ A recent D313Y case study ${ }^{20}$ investigated plasma levels of the FD biomarker lyso-Gb3, which has been described as a strong predictor of general disease severity and outcome in FD. ${ }^{29}{ }^{31}$ The results strengthened the assumption of D313Y being a non-pathological to low-pathological variant with good prognosis, since the lyso-Gb3 level was found normal in a patient with FD with the D313Y mutation, while it was elevated in 'classical' or severe, highly symptomatic patients with FD. ${ }^{20} 30{ }^{31}$ For that reason, the authors recommended initialising further or second genetic investigations in D313Y patients with severe organ involvement to detect potentially disease-relevant causative genotypes. ${ }^{20}$ Although the mild pathogenic nature of the D313Y mutation has been suggested before, its long-term impact on organ function remains largely unclear. Similar to other hereditary diseases, organ manifestations and symptoms may develop not before the fourth or fifth life decade.

\section{Cerebrovascular events and pain in D313Y}

In a recent study, an association of the D313Y mutation with multifocal white matter lesions on bMRI scans was suggested. ${ }^{19}$ These findings were not reflected in the current cohort: only one of six patients showed white matter lesions in the bMRI. Moreover, this participant did not have a history of cerebrovascular events. One patient did have a history of a suspected TIA (patient \#4). It is of note that a factor-V-Leiden mutation was also detected in this particular patient as an additional risk factor for thromboembolic events. ${ }^{38}$ Additionally, reported neurological symptoms of transient visual impairment and arm paresis in one participant could not be objectified clinically. The same held true for atypical acral pain, worsened in situations of physical or mental stress, which was reported by one additional participant. Since patients in the study cohort did not show typical neurological signs of FD, we suggest that the 
Table 3 Long-term FUP characteristics in participants with the D313Y genotype

\begin{tabular}{|c|c|c|c|c|c|c|}
\hline \multirow[b]{2}{*}{ Variable/participant (\#) } & \multicolumn{3}{|c|}{ Follow-up characteristics } & \multicolumn{3}{|l|}{ Mean \pm SD } \\
\hline & 1 & 2 & 3 & Baseline $(n=3)$ & Follow-up $(n=3)$ & p Value \\
\hline Follow-up time (years) & 5 & 5 & 2.5 & & $4.2 \pm 1.4$ & \\
\hline \multicolumn{7}{|l|}{ Demographics (mean/range) } \\
\hline Age (years) & 56 & 26 & 22 & $30 \pm 18$ & $35 \pm 19$ & 0.027 \\
\hline Gender (male/female) & Male & Female & Female & $1 / 3(33 / 66 \%)$ & $1 / 3(33 / 66 \%)$ & - \\
\hline BMI $\left(\mathrm{kg} / \mathrm{m}^{2}\right)$ & 20.5 & 24.9 & 20.8 & $23 \pm 1.7$ & $22 \pm 3$ & 0.236 \\
\hline \multicolumn{7}{|l|}{ Biomarkers (mean/range) } \\
\hline Serum lyso-Gb3 (ng/mL) & LLOQ & 0.23 & 0.8 & $0.6 \pm 0.5$ & $0.5 \pm 0.4$ & 0.487 \\
\hline NT-proBNP (pg/mL) & 49 & 48 & 30 & $103 \pm 110$ & $42 \pm 11$ & 0.477 \\
\hline \multicolumn{7}{|l|}{ Cardiovascular (mean/range) } \\
\hline $\mathrm{SBP}(\mathrm{mm} \mathrm{Hg})$ & 125 & 135 & 104 & $120 \pm 5$ & $121 \pm 16$ & 0.892 \\
\hline $\mathrm{DBP}(\mathrm{mm} \mathrm{Hg})$ & 75 & 85 & 73 & $81 \pm 6$ & $78 \pm 6$ & 0.095 \\
\hline HR (bpm) & 64 & 76 & 66 & $75 \pm 13$ & $69 \pm 6$ & 0.159 \\
\hline Malignant cardiac arrhythmia (\%) & no & no & no & 0 & 0 & - \\
\hline \multicolumn{7}{|l|}{ Echocardiography (mean/range) } \\
\hline LVEF (\%) & 55 & 65 & 63 & $66 \pm 5$ & $61 \pm 5$ & 0.417 \\
\hline IVSed (mm) & 7 & 8 & 7 & $7.6 \pm 1.5$ & $7.3 \pm 0.6$ & 0.423 \\
\hline LVPWed (mm) & 7 & 8 & 7 & $7.3 \pm 1.5$ & $7.3 \pm 0.6$ & 0.184 \\
\hline $\mathrm{E} / \mathrm{A}$ & 1.2 & 1.2 & 1.4 & $1.5 \pm 0.3$ & $1.3 \pm 0.1$ & 0.184 \\
\hline DT (ms) & 191 & 207 & 155 & $185 \pm 49$ & $184 \pm 27$ & 0.989 \\
\hline \multicolumn{7}{|l|}{ 2D-Speckle tracking (mean/range) } \\
\hline Global strain (\%) & -16.25 & -18.28 & -20.81 & $-20.6 \pm 2.46$ & $-18.45 \pm 2.28$ & 0.243 \\
\hline Global strain rate $\left(\mathrm{S}^{-1}\right)$ & -0.89 & -1.00 & -0.96 & $-1.09 \pm 0.1$ & $-0.95 \pm 0.06$ & 0.222 \\
\hline \multicolumn{7}{|l|}{ Cardiac MRI (mean/range) } \\
\hline LGE (\%) & no & no & no & 0 & 0 & - \\
\hline$n \operatorname{LVM}\left(\mathrm{g} / \mathrm{m}^{2}\right)$ & 53 & 49 & 49 & $48 \pm 6$ & $50 \pm 2$ & 0.844 \\
\hline $\mathrm{n} \operatorname{ESV}\left(\mathrm{mL} / \mathrm{m}^{2}\right)$ & 21 & 28 & 24 & $40 \pm 4$ & $24 \pm 4$ & 0.590 \\
\hline $\mathrm{n} \operatorname{EDV}\left(\mathrm{mL} / \mathrm{m}^{2}\right)$ & 66 & 74 & 67 & $116 \pm 3$ & $69 \pm 4$ & 0.410 \\
\hline $\mathrm{n} S V\left(\mathrm{~mL} / \mathrm{m}^{2}\right)$ & 45 & 47 & 43 & $76 \pm 6$ & $79 \pm 5$ & 0.205 \\
\hline $\mathrm{Cl}\left(\mathrm{L} / \mathrm{min} / \mathrm{m}^{2}\right)$ & 3.0 & 2.9 & 2.8 & $3.5 \pm 0.6$ & $2.9 \pm 0.1$ & 0.330 \\
\hline LVEF (\%) & 60 & 63 & 64 & $65 \pm 4$ & $62 \pm 2$ & 0.742 \\
\hline \multicolumn{7}{|l|}{ Renal (mean/range) } \\
\hline eGFR (mL/min/1.73 qm) & 75 & 88 & 106 & $106 \pm 7$ & $90 \pm 16$ & 0.320 \\
\hline Serum-creatinine (mg/dL) & 1.08 & 0.83 & 0.73 & $0.8 \pm 0.06$ & $0.9 \pm 0.18$ & 0.380 \\
\hline Cystatin C (mg/L) & 0.83 & 0.63 & 0.86 & $0.6 \pm 0.08$ & $0.8 \pm 0.13$ & 0.060 \\
\hline UPCR (mg/gL) & 47 & 38 & 76 & $63 \pm 21$ & $54 \pm 20$ & 0.824 \\
\hline \multicolumn{7}{|l|}{ Fabry-associated (\%) } \\
\hline Angiokeratoma & no & no & no & 0 & 0 & - \\
\hline Cornea verticillata & no & no & no & 0 & 0 & - \\
\hline Frequent diarrhoea & no & no & no & 33 & 0 & 1.000 \\
\hline Vertigo & yes & no & no & 33 & 33 & - \\
\hline Tinnitus & yes & no & no & 33 & 33 & - \\
\hline \multicolumn{7}{|l|}{ Neurology (\%) } \\
\hline Fabry-associated pain & no & no & no & 0 & 0 & - \\
\hline Hypohidrosis & no & no & no & 33 & 0 & 1.000 \\
\hline Heat intolerance & no & no & no & 33 & 0 & 1.000 \\
\hline Cold intolerance & no & no & no & 0 & 33 & 1.000 \\
\hline History of TIA & no & no & (yes) & 33 & 33 & - \\
\hline History of cerebrovascular insult & no & no & no & 0 & 0 & - \\
\hline
\end{tabular}

$\mathrm{BMI}$, body-mass-index in $\mathrm{kg} / \mathrm{m}^{2} ; \mathrm{Cl}$, cardiac index in cardiac MRI; DBP, diastolic blood pressure; DT, deceleration time; eGFR, estimated glomerular filtration rate (MDRD formula); HR, heart rate in bpm; IVSed, interventricular septum thickness in end-diastole; LGE, late gadolinium enhancement; LLOQ, lower limit of quantification; LVDED, left ventricular diameter in end-diastole; LVDES, left ventricular diameter in end-systole; LVEF, left ventricular ejection fraction; LVPWed, left ventricular posterior wall thickness in end-diastole; Lyso-Gb3 reference: $\leq 0.9 \mathrm{ng} / \mathrm{mL} ; \mathrm{n}$ EDV, normalised end-diastolic volume in cardiac MRI; $n$ ESV, normalised end-systolic volume in cardiac MRI; $\mathrm{n}$ LVM, normalised left ventricular mass in cardiac MRI; n SV, normalised stroke volume in cardiac MRI; NT-proBNP, N-terminal pro-brain natriuretic peptide, reference: age-dependent, $<125 \mathrm{pg} / \mathrm{mL}$; SBP, systolic blood pressure; SR, sinus rhythm; TIA, transient ischaemic attack; UPCR, urinary protein-to-creatinine ratio. 

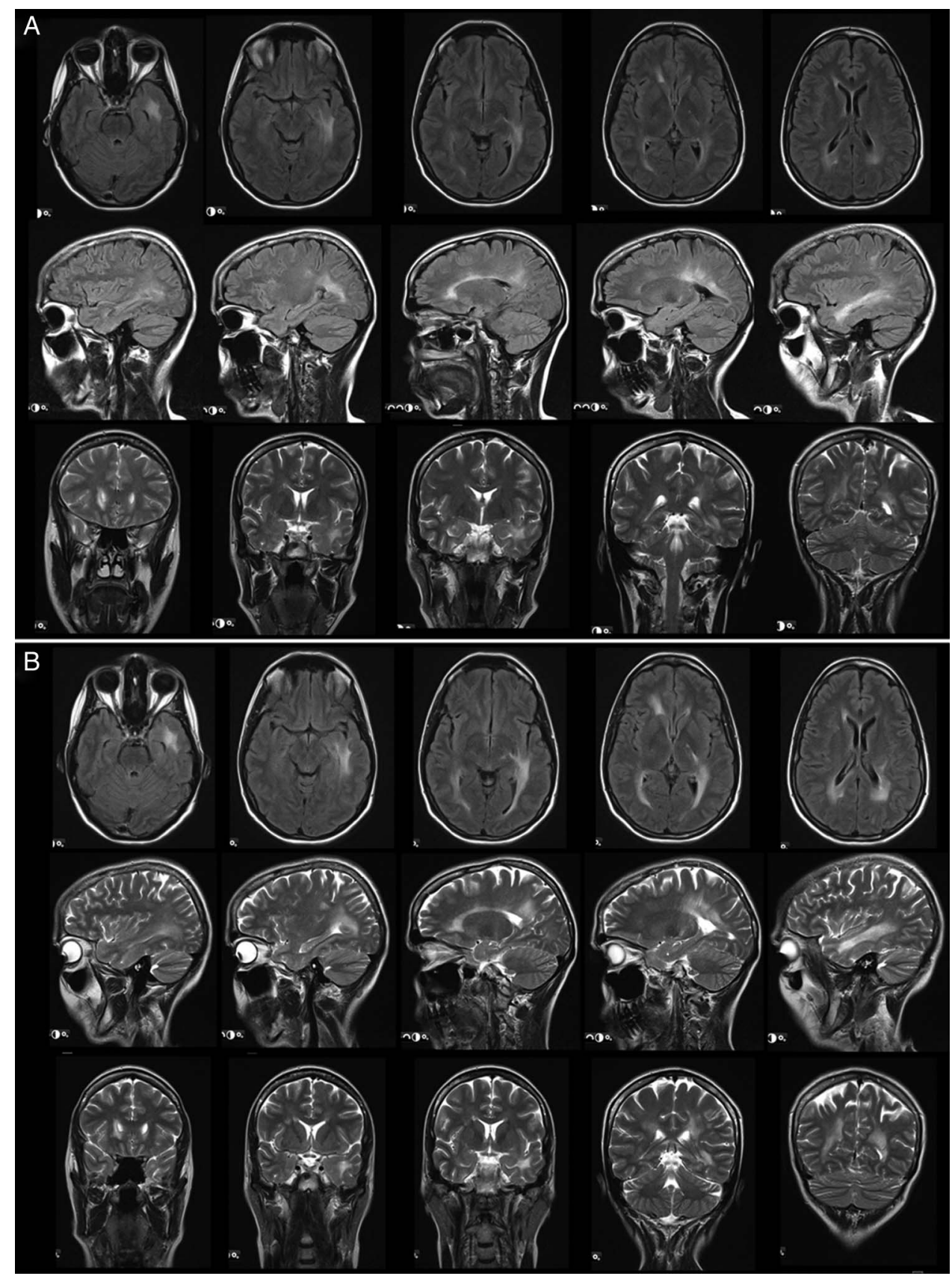

Figure 3 Brain MRI at baseline (3A) and long-term follow-up after 4 years (3B) in patient \#6. In various regions, areas of white matter lesions are apparent, which show no progress in number and extend between baseline and follow-up.

D313Y mutation is not linked with neurological involvement usually seen in patients with classical FD. Recent findings indicate that either an additional underlying causative genetic mutation or yet unknown modifying factors might be responsible for pain or cerebral involvement in D313Y patients. As an example, (homozygous) non-coding GLA polymorphisms might be considered as a potential undiagnosed pathology in such patients. ${ }^{39} 40$

\section{Cardiac and renal organ involvement in D313Y}

In this study population, no participant showed cardiac hypertrophy, or systolic or diastolic impairments, which are both usually seen in patients with FD.
The cardiospecific biomarkers NT-proBNP and hs-TnT were also in normal range. cMRI did not reveal morphological or functional abnormalities and showed no LGE. 2D-speckle tracking analysis also supplied normal strain rate values in these patients. Renal function was also nonpathological and proteinuria was not detectable in any patient during BL or the long-term FUP evaluation.

Taken together, the study results indicate that the D313Y genotype does not lead to FD-specific cardiac or renal involvement. Additional genetic or environmental factors might, however, still cause cardiac or renal organ destruction in these patients similar to that seen in classical FD variants. In this context, it is of note that 
endomyocardial and/or renal glomerular biopsy studies were not performed in this study population, but can elucidate pathological Gb3 deposition leading to incidental diagnosis of FD. Since the grade of deposition might reflect the grade of pathogenicity and thus the need for Fabry-specific ERT, biopsy studies might be clinically valuable and therefore indicated in cases of uncertain pathogenicity as seen in D313Y.

\section{HRQ oL and long-term outcome}

FD is known to be associated with a marked reduction of HRQoL when compared to healthy individuals from the general population. In this regard, the grade of organ involvement would be assumed to be a major indicator for impaired HRQoL as reported for stroke, reduced kidney function and cardiac involvement. Even though no major organ involvement was found in this study, the study individuals claimed a reduced HRQoL, as reflected by the results of the SF-36 questionnaires. The completed scores revealed reduced score dimensions in physical and mental well-being, suggesting that the genotype D313Y is somehow significant in regard to the patients' individually reported and perceived quality of life. However, with regard to the patients' family pedigrees-indicating the general well-being in the vast majority of participants (figure 2)-these results might also reflect the presence of co-founding variables/pathologies in these individuals, which might also be seen as the reason they were genetically tested in the first place, such as the Factor $\mathrm{V}$ Leiden mutation in one of the patients.

As reflected by the results from clinical investigations at a 4-year FUP, no disease progression was detectable over time in the patient population investigated. While unspecific symptoms generally remained in case no additional treatment was performed, no new or additional organ involvement was detectable at later time points. Cardiac morphology and function remained stable, including in patient \#3 who presented with elevated NT-proBNP levels at BL. Renal function remained stable within the normal range throughout the observation period. Patients remained neurologically normal, and in patient \#1 IENFD was proven to be stable over 5 years.

\section{Mutation-specific therapeutic options in D313Y}

FD has long been regarded as a diagnostic and therapeutic entity. Over the past years, several studies have raised an increasing understanding that there are several variants of GLA haplotype mutations, which might cause non-pathological, atypical, late-onset or organ-specific variants of FD. ${ }^{41-44}$ Availability of sensitive genetic methods and increasing data from large-scale screening studies in newborns or patients with chronic kidney disease, hypertrophic cardiomyopathy or cryptogenic stroke at young age has improved the identification of new FD phenotypes. ${ }^{10} 42$ 44-51 Future characterisation of so far poorly understood non-typical genetic variants is crucial to link genetics and pathophysiology to appropriate individualised therapeutic concepts in FD. As an example, depending on the genotype, particularly male patients with FD might in many cases be in need of ERT even before the onset of symptoms, to prevent organ involvement at the earliest possible time point. In other genetic backgrounds, patients might generally not benefit from ERT at all but could, for example, benefit from supportive medical pain therapy.

In this context, the results of this study clearly suggest that the D313Y mutation leads to a non-pathological or mild variant of FD at most, with a presumably good prognosis and no need for ERT. The lack of typical FD-associated angiokeratoma and/or cornea verticillata in the study population furthermore strengthens the hypothesis of D313Y not being a classical variant of FD. From family pedigrees, it might even be speculated that the D313Y genotype is much more common in the general population than currently known, but never diagnosed in most individuals due to its benign nature. However, it is worth noting that one of six patients had a history suggestive of a TIA or even stroke. Even though this might have been due to a Factor V Leiden mutation, the possibility remains that the D313Y genotype might have played a triggering or promoting role which is not yet understood.

\section{CONCLUSIONS}

The results of this study suggest that the D313Y genotype does not lead to severe organ manifestations as seen in GLA haplotype variants known to cause classical FD. However, owing to the sporadic incidence of neurological symptoms or young-aged cerebrovascular ischaemic events, D313Y might have a significant impact on HRQoL in respective individual patients, where this mutation might represent a co-founding risk factor for certain isolated symptoms triggering a specific mild clinical variant of FD.

Acknowledgements The authors thank Mrs Irina Turkin for her long-standing elaborate work in FAZIT.

Contributors DO and PN contributed to the study design, data collection, analysis, interpretation, drafting and revision of the manuscript. NÜ, DL, KH, $\mathrm{BP}, \mathrm{CS}, \mathrm{GE}$ and $\mathrm{CW}$ contributed to the data collection, analysis, interpretation and revision of the manuscript. All authors approved the final version of the manuscript.

Funding This study was supported by the Federal Ministry of Education and Research of the Federal Republic of Germany (BMBF 01E01504, M02).

Competing interests D0 received travel assistance from Genzyme Corporation, Cambridge, Massachusetts, and Shire PIc., Dublin, Ireland. NÜ received travel assistance, speaker's/advisory board honoraria and research support from Genzyme and Shire. CS received speaker's/advisory board honoraria and research support from Genzyme. CW received travel assistance, speaker's/advisory board honoraria and research support from Genzyme and Shire. PN received travel assistance, speaker's/advisory board honoraria and research support from Genzyme and Shire. The other authors report no conflict.

Patient consent Obtained. 
Ethics approval The investigations were approved by the local ethics committee of the University and University Hospital Würzburg, Bavaria, Germany. All patients gave written informed consent.

Provenance and peer review Not commissioned; externally peer reviewed.

Data sharing statement No additional data are available.

Open Access This is an Open Access article distributed in accordance with the Creative Commons Attribution Non Commercial (CC BY-NC 4.0) license, which permits others to distribute, remix, adapt, build upon this work noncommercially, and license their derivative works on different terms, provided the original work is properly cited and the use is non-commercial. See: http:// creativecommons.org/licenses/by-nc/4.0/

\section{REFERENCES}

1. Brady RO, Gal AE, Bradley RM, et al. Enzymatic defect in Fabry's disease. Ceramidetrihexosidase deficiency. N Engl J Med 1967;276:1163-7.

2. Kint JA. Fabry's disease: alpha-galactosidase deficiency. Science 1970;167:1268-9.

3. Desnick RJ, Brady R, Barranger J, et al. Fabry disease, an under-recognized multisystemic disorder: expert recommendations for diagnosis, management, and enzyme replacement therapy. Ann Intern Med 2003;138:338-46.

4. Germain DP. Fabry disease. Orphanet J Rare Dis 2010:5:30.

5. Tuttolomondo A, Pecoraro R, Simonetta I, et al. Anderson-Fabry disease: a multiorgan disease. Curr Pharm Des 2013;19:5974-96.

6. MacDermot KD, Holmes A, Miners AH. Anderson-Fabry disease: clinical manifestations and impact of disease in a cohort of 60 obligate carrier females. J Med Genet 2001;38:769-75.

7. MacDermot KD, Holmes A, Miners AH. Anderson-Fabry disease: clinical manifestations and impact of disease in a cohort of 98 hemizygous males. J Med Genet 2001;38:750-60.

8. Uceyler N, Ganendiran S, Kramer D, et al. Characterization of pain in fabry disease. Clin J Pain 2014;30:915-20.

9. Tuttolomondo A, Pecoraro R, Simonetta I, et al. Neurological complications of Anderson-Fabry disease. Curr Pharm Des 2013;19:6014-30.

10. Rolfs A, Bottcher T, Zschiesche M, et al. Prevalence of Fabry disease in patients with cryptogenic stroke: a prospective study. Lancet 2005;366:1794-6.

11. Weidemann F, Ertl G, Wanner C, et al. The Fabry cardiomyopathydiagnostic approach and current treatment. Curr Pharm Des 2015;21:473-8.

12. Linhart A, Kampmann C, Zamorano JL, et al. Cardiac manifestations of Anderson-Fabry disease: results from the international Fabry outcome survey. Eur Heart J 2007;28:1228-35.

13. Schiffmann R, Warnock DG, Banikazemi M, et al. Fabry disease: progression of nephropathy, and prevalence of cardiac and cerebrovascular events before enzyme replacement therapy. Nephrol Dial Transplant 2009;24:2102-11.

14. Mehta A, Clarke JT, Giugliani R, et al. Natural course of Fabry disease: changing pattern of causes of death in FOS-Fabry Outcome Survey. J Med Genet 2009;46:548-52.

15. Genomes Project C, Abecasis GR, Auton A, et al. An integrated map of genetic variation from 1,092 human genomes. Nature 2012;491:56-65.

16. accessed 19th October 2015). http://fabry-database.org

17. Froissart R, Guffon N, Vanier MT, et al. Fabry disease: D313Y is an alpha-galactosidase $A$ sequence variant that causes pseudodeficient activity in plasma. Mol Genet Metab 2003:80:307-14.

18. Yasuda M, Shabbeer J, Benson SD, et al. Fabry disease: characterization of alpha-galactosidase $\mathrm{A}$ double mutations and the D313Y plasma enzyme pseudodeficiency allele. Hum Mutat 2003:22:486-92.

19. Lenders M, Duning T, Schelleckes M, et al. Multifocal White matter lesions associated with the D313Y mutation of the $\alpha$-galactosidase A gene. PLOS ONE 2013;8:e55565

20. Niemann M, Rolfs A, Giese A, et al. Lyso-Gb3 Indicates that the Alpha-Galactosidase A Mutation D313Y is not Clinically Relevant for Fabry Disease. JIMD Rep 2013;7:99-102.

21. Lang RM, Badano LP, Mor-Avi V, et al. Recommendations for cardiac chamber quantification by echocardiography in adults: an update from the American Society of Echocardiography and the European Association of Cardiovascular Imaging. Eur Heart $J$ Cardiovasc Imaging 2015;16:233-70.
22. Lang RM, Badano LP, Mor-Avi V, et al. Recommendations for cardiac chamber quantification by echocardiography in adults: an update from the American Society of Echocardiography and the European Association of Cardiovascular Imaging. J Am Soc Echocardiogr 2015;28:1-39.e14

23. Kosmala W, Plaksej R, Strotmann JM, et al. Progression of left ventricular functional abnormalities in hypertensive patients with heart failure: an ultrasonic two-dimensional speckle tracking study. $J$ Am Soc Echocardiogr 2008;21:1309-17.

24. Kramer J, Niemann M, Liu D, et al. Two-dimensional speckle tracking as a non-invasive tool for identification of myocardial fibrosis in Fabry disease. Eur Heart J 2013;34:1587-96.

25. Rolke R, Baron R, Maier C, et al. Quantitative sensory testing in the German Research Network on Neuropathic Pain (DFNS): standardized protocol and reference values. Pain 2006;123:231-43.

26. Uceyler N, Kafke W, Riediger N, et al. Elevated proinflammatory cytokine expression in affected skin in small fiber neuropathy. Neurology 2010;74:1806-13.

27. Lauria G, Cornblath DR, Johansson O, et al., European Federation of Neurological Societies. EFNS guidelines on the use of skin biopsy in the diagnosis of peripheral neuropathy. Eur J Neurol 2005;12:747-58.

28. Fazekas F, Chawluk JB, Alavi A, et al. MR signal abnormalities at $1.5 \mathrm{~T}$ in Alzheimer's dementia and normal aging. AJR Am J Roentgenol 1987;149:351-6.

29. Aerts JM, Groener JE, Kuiper S, et al. Elevated globotriaosylsphingosine is a hallmark of Fabry disease. Proc Natl Acad Sci U S A 2008;105:2812-17.

30. Togawa T, Kodama T, Suzuki T, et al. Plasma globotriaosylsphingosine as a biomarker of Fabry disease. $\mathrm{Mol}$ Genet Metab 2010;100:257-61.

31. Niemann M, Rolfs A, Störk S, et al. Gene mutations versus clinically relevant phenotypes: lyso-Gb3 defines Fabry disease. Circ Cardiovasc Genet 2014;7:8-16.

32. McHorney CA, Ware JE Jr, Rogers W, et al. The validity and relative precision of MOS short- and long-form health status scales and Dartmouth COOP charts. Results from the Medical Outcomes Study. Med Care 1992;30(Suppl):MS253-65.

33. Gabbay E, Meyer KB, Griffith JL, et al. Temporal trends in health-related quality of life among hemodialysis patients in the United States. Clin J Am Soc Nephrol 2010:5:261-7.

34. Watt T, Burlina AP, Cazzorla C, et al. Agalsidase beta treatment is associated with improved quality of life in patients with Fabry disease: findings from the Fabry Registry. Genet Med 2010;12:703-12.

35. Ware J Jr, Kosinski M, Keller SD. SF-36 physical and mental health summary scales, a user's manual. Booston, MA: The Health Institute, 1994.

36. Magerl W, Krumova EK, Baron R, et al. Reference data for quantitative sensory testing (QST): refined stratification for age and a novel method for statistical comparison of group data. Pain 2010;151:598-605.

37. Eng CM, Resnick-Silverman LA, Niehaus DJ, et al. Nature and frequency of mutations in the alpha-galactosidase $\mathrm{A}$ gene that cause Fabry disease. Am J Hum Genet 1993;53:1186-97.

38. Lenders $\mathrm{M}$, Karabul $\mathrm{N}$, Duning $\mathrm{T}$, et al. Thromboembolic events in Fabry disease and the impact of factor V Leiden. Neurology 2015;84:1009-16

39. Schelleckes M, Lenders M, Guske K, et al. Cryptogenic stroke and small fiber neuropathy of unknown etiology in patients with alpha-galactosidase A -10T genotype. Orphanet J Rare Dis 2014;9:178.

40. Tuttolomondo A, Duro G, Pecoraro R, et al. A family with various symptomatology suggestive of Anderson-Fabry disease and a genetic polymorphism of alpha galactosidase A gene. Clin Biochem 2015;48:55-62.

41. Germain DP. A new phenotype of Fabry disease with intermediate severity between the classical form and the cardiac variant. Contrib Nephrol 2001(136):234-40

42. Lin HY, Chong KW, Hsu JH, et al. High incidence of the cardiac variant of Fabry disease revealed by newborn screening in the Taiwan Chinese population. Circ Cardiovasc Genet 2009;2:450-6.

43. Thomas A, Baker R, Mehta A, et al. The N215S mutation results in a distinct subtype of Fabry disease. Mol Genet Metab 2015;114S113.

44. Hwu WL, Chien YH, Lee NC, et al. Newborn screening for Fabry disease in Taiwan reveals a high incidence of the later-onset GLA mutation c.936+919G>A (IVS4+919G>A). Hum Mutat 2009;30:1397-405.

45. Andrade J, Waters PJ, Singh RS, et al. Screening for Fabry disease in patients with chronic kidney disease: limitations of plasma alpha-galactosidase assay as a screening test. Clin J Am Soc Nephrol 2008;3:139-45. 
46. Auray-Blais C, Millington DS, Young SP, et al. Proposed high-risk screening protocol for Fabry disease in patients with renal and vascular disease. J Inherit Metab Dis 2009;32:303-8.

47. Bekri S, Enica A, Ghafari T, et al. Fabry disease in patients with end-stage renal failure: the potential benefits of screening. Nephron Clin Pract 2005;101:c33-8.

48. Bouwman MG, de Ru MH, Linthorst GE, et al. Fabry patients experiences with the timing of diagnosis relevant for the discussion on newborn screening. Mol Genet Metab 2013;109: 201-7.
49. Kotanko P, Kramar R, Devrnja D, et al. Results of a nationwide screening for Anderson-Fabry disease among dialysis patients. $J$ Am Soc Nephrol 2004;15:1323-9.

50. Merta M, Reiterova J, Ledvinova J, et al. A nationwide blood spot screening study for Fabry disease in the Czech Republic haemodialysis patient population. Nephrol Dial Transplant 2007:22:179-86.

51. Spada M, Pagliardini S, Yasuda M, et al. High incidence of later-onset fabry disease revealed by newborn screening. Am J Hum Genet 2006;79:31-40. 